\title{
The availability of
}

\section{prescription-only analgesics} \section{purchased from the internet in the UK}

\author{
Connie Raine, David J. Webb \& Simon R. J. Maxwell \\ Clinical Research Centre, University of Edinburgh, Western General Hospital, Edinburgh, UK
}

\section{WHAT IS ALREADY KNOWN ABOUT THIS SUBJECT}

- Increasing numbers of people are accessing medicines from the internet.

- This online market is poorly regulated and represents a potential threat to the health of patients and members of the public.

\section{WHAT THIS STUDY ADDS}

- Prescription-only analgesics, including controlled opioids, are readily available to the UK public through internet pharmacies that are easily identified by popular search engines.

- The majority of websites do not require the customer to possess a valid prescription for the drug.

- Less than half provide an online health screen to assess suitability for supply.

- The majority have no registered geographical location.

- Analgesic medicines are usually purchased at prices significantly above British National Formulary prices and are often supplied in large quantities.

- These findings are of particular relevance to pain-management specialists who are trying to improve the rational use of analgesic drugs.

\section{Correspondence}

Dr Simon Maxwell, MD, PhD, FRCP, FRCPE, Clinical Research Centre, Western General Hospital, Crewe Road South, Edinburgh EH42XU, UK.

Tel: + 4401315371718

E-mail: s.maxwell@ed.ac.uk

Contributors: S.R.J.M. conceived the idea for the study. S.R.J.M. and C.R. developed the study design with input from D.J.W. C.R. made all the observations. C.R. produced the first draft of the manuscript, which was developed and refined with input from S.R.J.M. and D.J.W.

\section{Keywords}

analgesic, drugs, internet, pharmacy, prescription, public health

\section{Received}

7 April 2008

Accepted 20 October 2008

Published Early View

19 December 2008

\section{AIMS}

To explore the availability to the UK population of prescription-only analgesics from the internet.

\section{METHODS}

Websites were identified by using several keywords in the most popular internet search engines. From 2000 websites, details of 96 were entered into a database.

\section{RESULTS}

Forty-six (48\%) websites sold prescription analgesics, including seven opioids, two non-opioids and 18 nonsteroidal anti-inflammatory drugs. Thirty-five (76\%) of these did not require the customer to possess a valid prescription.

\section{CONCLUSION}

Prescription-only analgesics, including controlled opioids, are readily available from internet websites, often without a valid prescription. 


\section{Introduction}

Internet usage has rapidly expanded in recent years, and $>66 \%$ of the UK population are now regular users [1]. This trend has allowed the growth of internet pharmacies that offer a convenient and anonymous way of purchasing a range of medicines. These include 'prescription-only medicines' (POMs), which, by law, require a valid prescription and risk-benefit assessment by a trained healthcare professional before they can be supplied in most developed countries. The need for a prescription is being bypassed by unregulated websites [2-5], which poses a potential risk to public health. There is already evidence that internet drug purchases have caused significant morbidity and mortality [6].

Analgesic drugs are frequently used by UK patients and in 2006/2007 were among the 10 most commonly prescribed drugs in Scotland by both cost and volume [7]. The aim of this study was to explore the availability to the public of prescription-only analgesics on the internet through popular search engines. The focus was on opioid analgesics, non-opioid analgesics and nonsteroidal antiinflammatory drugs (NSAIDS).

\section{Methods}

Websites were identified by searching the internet with the two most popular search engines, Google and Yahoo [8], and 16 different keywords. Two thousand websites were investigated and a database (Microsoft Excel Spread- sheet) was created containing details of 96 that met three inclusion criteria: (i) they sold analgesics to the public, (ii) they delivered orders to UK addresses, and (iii) they provided free access. Details included: website name and URL; physical address; analgesics available; quantities and cost; prescription requirements; questionnaire requirements; and the amount of information about the drugs. A simple descriptive analysis of data was performed.

\section{Results}

\section{General findings}

General findings are illustrated in Figure 1.The search strategy identified 96 websites that sold analgesics to the UK population. Forty-six (48\%) websites sold POMs and 50 $(52 \%)$ sold only over-the-counter (OTC) medicines.

\section{Prescription-only analgesics (46 websites)}

Twenty-seven different POMs were available: seven opioids, two non-opioids and 18 NSAIDs. Key characteristics of these drugs are listed in Table 1. Thirty-five (76\%) websites did not require the customer to possess a valid prescription. Twenty-six (57\%) provided no information as to the physical location of the company. Fifteen (33\%) did not provide any online information regarding instructions for use, side-effects, contraindications or interactions; the remaining 31 (67\%) provided varying amounts of information. Nineteen $(41 \%)$ required the customer to undertake some form of health screening. This took the form of an online questionnaire, or 'consultation'.

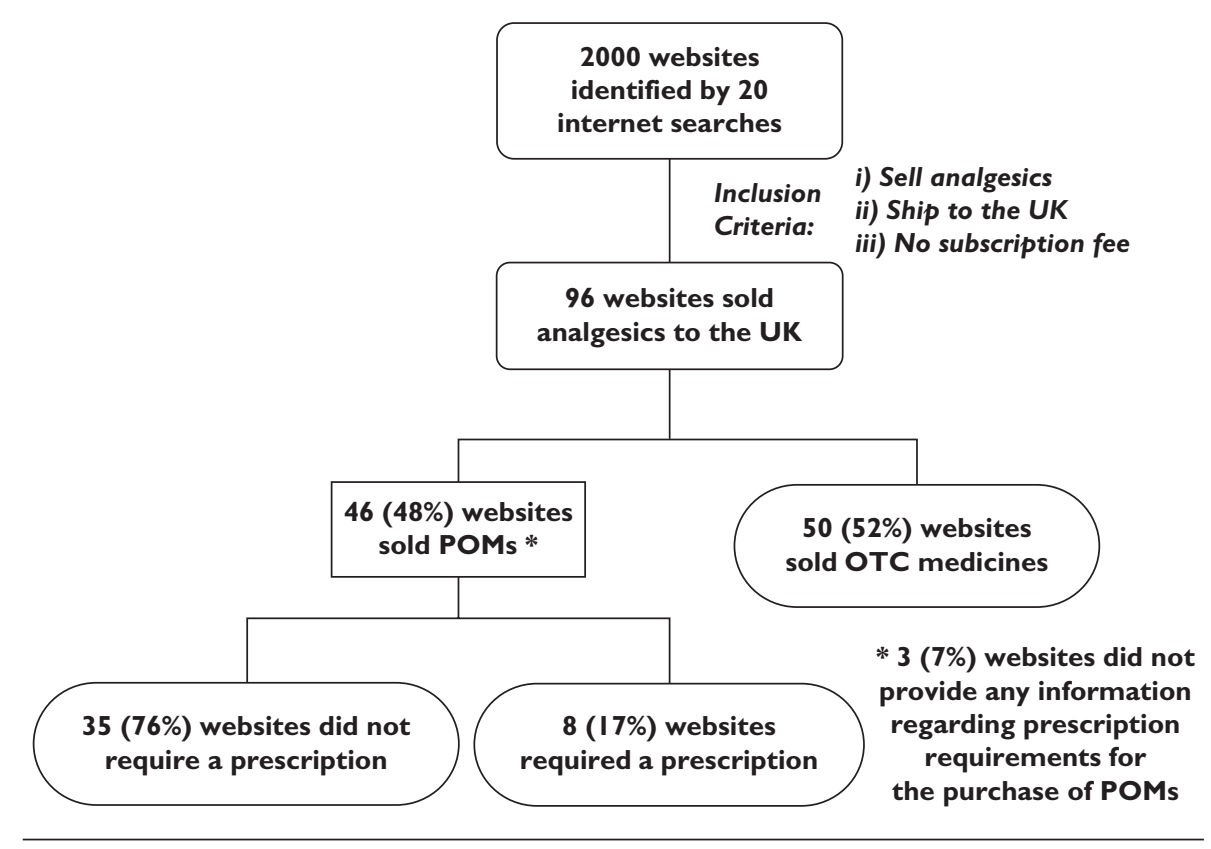

\section{Figure 1}

Flowchart summarizing the search and results 


\section{Table 1}

Prescription-only medicines available with and without a prescription

\begin{tabular}{|c|c|c|c|c|c|c|}
\hline Drug class & Drug name & Dose* & Form & Pricet & Quantity $\ddagger$ & Sites $\S$ \\
\hline \multicolumn{7}{|c|}{ No prescription } \\
\hline \multirow[t]{8}{*}{ Opioid } & Tramadol & $200 \mathrm{mg}$ & Tablet & $\mathrm{f} 0.20$ & $1000(50 \mathrm{mg})$ & 24 \\
\hline & Tramadol & $2 \mathrm{ml}, 100 \mathrm{mg}$ & Injection & f2.97 & $15(100 \mathrm{mg})$ & 2 \\
\hline & Codeine & $50 \mathrm{mg}$ & Tablet & f1.03 & 240 (14 mg) & 5 \\
\hline & Codeine & $125 \mathrm{ml}$ & Syrup & f29.00 & 1 bottle & 1 \\
\hline & Buprenorphine & $0.2 \mathrm{mg}$ & Tablet & $f 0.74$ & $200(0.2 \mathrm{mg})$ & 1 \\
\hline & Pentazocine & $25 \mathrm{mg}$ & Tablet & $f 0.30$ & $250(25 \mathrm{mg})$ & 1 \\
\hline & Butorphanol & $1 \mathrm{mg}$ & Injection & f3.47 & - & 1 \\
\hline & Nalbuphine & $1 \mathrm{ml}$ & Injection & f3.47 & 5 (1 ml) & 1 \\
\hline \multirow[t]{2}{*}{ Non-opioid } & Co-codamol & $30 / 650 \mathrm{mg}$ & Tablet & f1.04 & $720(30 / 500 \mathrm{mg})$ & 5 \\
\hline & Co-proxamol & $65 / 400 \mathrm{mg}$ & Tablet & f0.35 & $100(30 \mathrm{mg})$ & 3 \\
\hline \multirow[t]{13}{*}{ NSAIDs } & Celecoxib & $200 \mathrm{mg}$ & Tablet & $f 0.20$ & $300(100 \mathrm{mg})$ & 24 \\
\hline & Diclofenac & $100 \mathrm{mg}$ & Tablet & $f 0.18$ & 300 (75 mg) & 12 \\
\hline & Ketorolac & $10 \mathrm{mg}$ & Tablet & $f 0.65$ & $180(10 \mathrm{mg})$ & 4 \\
\hline & Mefenamic acid & $500 \mathrm{mg}$ & Tablet & f0.79 & $30(250,500 \mathrm{mg})$ & 4 \\
\hline & Ketoprofen & $200 \mathrm{mg}$ & Tablet & $f 0.68$ & $90(200 \mathrm{mg})$ & 4 \\
\hline & Metamizole & $0.5 \mathrm{mg}$ & Tablet & $f 0.25$ & $10(0.5 \mathrm{mg})$ & 3 \\
\hline & Nabumetone & $500 \mathrm{mg}$ & Tablet & $f 0.37$ & $90(500 \mathrm{mg})$ & 4 \\
\hline & Diflunisal & $500 \mathrm{mg}$ & Tablet & $\mathrm{f} 0.50$ & $60(500 \mathrm{mg})$ & 1 \\
\hline & Dexketoprofen & $25 \mathrm{mg}$ & Tablet & $f 0.82$ & $60(25 \mathrm{mg})$ & 1 \\
\hline & Tolmetin & $200 \mathrm{mg}$ & Tablet & $f 0.21$ & $60(200 \mathrm{mg})$ & 1 \\
\hline & Tenoxicam & $20 \mathrm{mg}$ & Tablet & f0.19 & 90 (20 mg) & 1 \\
\hline & Tiaprofenic Acid & $300 \mathrm{mg}$ & Tablet & $f 0.25$ & $100(300 \mathrm{mg})$ & 1 \\
\hline & Refecoxib & $50 \mathrm{mg}$ & Tablet & f1.63 & $30(25,50 \mathrm{mg})$ & 1 \\
\hline \multicolumn{7}{|l|}{ Prescription } \\
\hline Opioid & Tramadol & $50 \mathrm{mg}$ & Tablet & f0.13 & $1200(50$ mg) & 5 \\
\hline \multirow{3}{*}{ NSAIDs } & Indomethacin & $75 \mathrm{mg}$ & Tablet & f0.07 & 400 (75 mg) & 2 \\
\hline & Tiaprofenic acid & $300 \mathrm{mg}$ & Tablet & f0.24 & $500(300 \mathrm{mg})$ & 2 \\
\hline & Etoricoxib & $90 \mathrm{mg}$ & Tablet & f1.40 & $30(60,90 \mathrm{mg})$ & 1 \\
\hline
\end{tabular}

* Largest dose of drug available. +Based upon the cheapest price for the lowest dose. Prices converted to Pound Sterling using British Broadcasting Corporation Exchange Rate on

27 July 2007. ₹Largest quantity of drug of any dose available in number of tablets/injections/bottles. §Number of websites which sell each drug.

Eight (17\%) websites required customers in the UK to possess a prescription for POMs. Six accepted a faxed or e-mailed prescription from the customer; one required either the prescription to be posted by the customer or a telephone call or fax from the customer's doctor; and one did not provide details.

\section{Discussion}

This study revealed that prescription-only analgesics, including controlled analgesics with addictive potential (e.g. codeine, buprenorphine, pentazocine and dextropropoxyphene), were readily available for sale to members of the public from the internet, often without a valid prescription.

According to UK statute law, POMs may be sold or supplied 'only in accordance with a prescription given by an appropriate practitioner' [9]. Over three-quarters of the websites were prepared to bypass these regulations, allowing members of the public to self-prescribe. Most of those sites that required a prescription were prepared to accept a fax or e-mail in direct contravention of the recommendations of the Royal Pharmaceutical Society of Great Britain 
about what constitutes a valid prescription [10]. Such prescriptions can be sent simultaneously to different pharmacies and be forged [5].

Customers could also purchase a larger quantity of a drug in a single order from a website than would usually be permitted with a prescription, allowing stockpiling (e.g. it was possible to buy $100050-\mathrm{mg}$ tramadol tablets without a prescription). These findings are of particular concern at a time when addiction to opioid analgesics presents a major challenge to public health and considerable efforts are being made to ensure that their use follows rational guidelines. The British Pain Society [11] recommends a thorough physical, psychological and social assessment of the patient by a healthcare professional, development of a treatment plan prior to commencing opioid therapy, and regular assessment after commencement of therapy.

There are certain advantages to purchasing drugs online $[3,12]$. Internet pharmacies offer: convenient access to a large variety of products $24 \mathrm{~h}$ a day; good accessibility for those in rural areas or who are house bound; anonymity; and various product and health information. Despite these apparent benefits, many problems arise.

The quality of drugs purchased from the internet is cause for concern [13]. The US Food and Drug Administration (FDA) [14] has warned customers that medicines may be counterfeit, contaminated, contain the wrong active ingredient, or contain too much, too little or no active ingredient. The difficulties in tracing the source of drugs in order to determine quality is exemplified by the fact that $57 \%$ of websites in our study that sold POMs did not provide a physical address of the company or pharmacy. There is also a need to control the 'accuracy, completeness and consistency' of online public healthcare information [15]. The amount of information varied greatly between websites; $28 \%$ of websites provided none at all prior to purchase. Buprenorphine could be bought from two websites, neither of which provided any online information prior to purchase (although some information may be supplied on delivery).

The FDA [12] is concerned about the substitution of a face-to-face patient-doctor consultation with an online questionnaire. This study revealed that $54 \%$ of websites that sold POMs without a prescription required the customer to undertake a simple health questionnaire covering height, weight, sex, current drug therapy and past medical and surgical history. However, such questionnaires would allow customers to obtain prescriptions on the basis of false or incorrect information [4]. The remaining $46 \%$ sold POMs without any form of screening. Whether or not a questionnaire is used, the lack of a face-to-face consultation can lead to inappropriate medication use and adverse events [3].

Finally, Bloom and lannacone [4] found that drugs purchased on the internet were consistently more expensive. Our study showed that this applies equally to analgesics. For example, tramadol, a widely available opioid (Table 1), varied in price from $£ 0.13$ to $£ 1.63$ for one 50 -mg tablet. The British National Formulary price is $£ 0.04$.

\section{Study limitations}

More than 2000 websites were identified using the two most popular search engines, but other search engines may have generated different results. Using our inclusion criteria, a limited cohort of 96 websites were selected for investigation in detail. Although the search strategy was chosen to simulate that of a motivated member of the public, website advertisements and e-mails might also identify internet pharmacies. Furthermore, whereas this study focused on 'anchor' sites [4], we cannot be certain that some portal sites or other duplicate sites were not included.

\section{Conclusion}

Prescription-only analgesics, including controlled opioids, are readily available without a prescription to the UK public from internet websites easily identified through popular search engines. The lack of regulation of opioid use, the large quantities available and the subsequent risk to patients present a major and growing threat to public health. Although internet pharmacies offer potential advantages in some circumstances, the current unregulated market leaves consumers vulnerable to the supply of medicines that are medically inappropriate, of poor quality and provided without accurate information.

\section{Competing interests}

None to declare.

\section{REFERENCES}

1 Internet World Stats. Internet usage in Europe. 2007. Available at http://www.internetworldstats.com/stats4.htm (last accessed 16 July 2007).

2 Armstrong KA, Schwartz JS, Asch DA. Direct sale of sildenafil (Viagra) to consumers over the internet. N Engl J Med 1999; 341: 1389-92.

3 Bessell T, Silagy C, Anderson J, Hiller J, Sansom L. Quality of global e-pharmacies: can we safeguard consumers? Eur J Clin Pharmacol 2002; 58: 567-72.

4 Bloom B, lannacone R. Internet availability of prescription pharmaceuticals to the public. Ann Intern Med 1999; 131: 830-3. 
5 International Narcotics Control Board. Internationally Controlled Drugs and the Unregulated Market. Vienna: INCB, 2006. Available at http://www.incb.org/pdf/e/ar/2006/ annual-report-2006-en-1.pdf (last accessed 25 October 2007).

6 Theodosiou J, Green J. Emerging challenges in using health information from the internet. Adv Psychiatr Treat 2003; 9: 387-96.

7 NHS National Services Scotland Information Services Division. Top Ten Drugs. Edinburgh: NSS, 2007. Available at http://www.isdscotland.org/isd/informationandstatistics.jsp? pContentID=2229\&p_applic=CCC\&p_service $=$ Content.show \& (last accessed 27 October 2007).

8 Sullivan D. Nielson NetRatings. Neilson NetRatings Search Engine Ratings. Search Engine Watch, 2006. Available at http://searchenginewatch.com/showPage.html?page= 2156451 (last accessed 29 May 2007).

9 Ministry of Justice UK Statute Law Database. The Prescription Only Medicines (Human Use) Order 1997. London: Ministry of Justice, 1997. Available at http://www. statutelaw.gov.uk (last accessed 29 October 2007).

10 Royal Pharmaceutical Society of Great Britain. RPSGB Medicines, Ethics and Practice: A Guide for Pharmacists and
Pharmacy Technicians. London: RPSGB, 2007. Available at http://www.rpsgb.org/informationresources/ downloadsocietypublications (last accessed 29 October 2007).

11 The British Pain Society. Recommendations for the Appropriate Use of Opioids for Persistent Non-cancer Pain. London: British Pain Society, 2004. Available at http://www.britishpainsociety.org/book_opioid_main.pdf (last accessed 4 August 2008).

12 Henney J. Cyberpharmacies and the role of the US Food and Drug Administration. J Med Internet Res 2001; 3: E3.

13 Young D. FDA clarifies importation laws as internet pharmacies proliferate. Am J Health Syst Pharm 2003; 60: 729-30.

14 U.S. Food and Drug Administration. The Possible Dangers of Buying Medicine Online. Rockville, MD: FDA, 2007. Available at http://www.fda.gov/consumer/features/ drugsonline0707.html (last accessed 25 October 2007).

15 Impicciatore P, Pandolfini C, Casella N, Bonati M. Reliability of health information for the public on the world wide web: systematic survey of advice on managing fever in children at home. BMJ 1997; 314: 1875. 